\title{
Linguagens e representações: silenciamento e margem
}

\section{SandRa Sacramento}

Professora doutora em Literatura Brasileira pela

UFRJ, Titular da Universidade Estadual de Santa

Cruz/Uesc.

Resumo: Discussão sobre a origem das metanarrativas encarregadas de plasmar um ideário teleológico-historicista e apoiadas no etnocentrismo e no logofonocentrismo, pondo-se sob a visão do contexto do século $X X$, mediante análise do pós-estruturalismo e da teoria da desconstrução e de outros estudos que fizeram incidir criticas severas ao modelo de racionalidade anterior e deram respaldo ao movimento de minorias, ainda não contempladas pela racionalidade ocidental, entre as quais a versão do pós-feminismo.

Palavras-chave: Historicismo; metanarrativas; estruturalismo; pós-estruturalismo; desconstrução; pós-feminismo
Abstract: This article places metanarratives' sources, which are delegated to demonstrate a teleological historicism, which truth has legitimized ethnocentrism and logofonocentrism. In the 20th century, post-structuralism, deconstruction theory and other researches strongly criticized the past rationality model and they supported minority ideas, as the post-feminism, which had not approached by Occidental rationality.

Key words: Historicism; metanarratives; structuralism; post-structuralism, deconstruction; post-feminism. 

Ai, palavras, ai palavras, que estranha potência, a vossa!

Cecília Meireles

Digo: o real não está na saída nem na chegada: ele se dispóe para a gente é no meio da travessia.

João Guimarães Rosa

\section{Historicismo e metanarrativas}

As metanarrativas, sistemas discursivos de legitimação, foram postas a serviço do Ocidente e impuseram a absolutização dos lugares enunciativos, em que o dissenso e a fragmentação se tornaram banidos em nome da ordem e da exclusão. Desde a Antiguidade Clássica, o relato mítico, a filosofia e o cânone ocidental literário encerraram, a princípio, tal desiderato, como os grandes balizadores comportamentais a prescrever e a encerrar a melhor maneira de dar sentido ao mundo.

A modernidade, por suavez, em sua crença eprática ideológico-culturais, encarregou-se de vincular o relato historicista das metanarrativas aos ideais iluministas, com o otimismo em relação ao papel da ciência e com a crença no progresso ou na busca de verdades, de valores universais e atemporais. Jean Françoise Lytoard, em $A$ condição pós-moderna (1998), identifica duas narrativas que nortearam a modernidade cientificamente: a narrativa política, encerrada no discurso emancipatório da Revolução Francesa, e a narrativa filosófica, esteandose na obra de Hegel, Fenomenologia do espírito (2003), quando situa o conhecimento em uma dimensão histórico-evolucionista.

A partir do século XVII, a visão historicista do mundo e a construção dos Estados-nação europeus, fundamentadas em uma língua nacional e em limites territoriais, levaram a acreditar em promessas da igualdade universal; e, para tanto, empenharam-se, através de crenças e práticas ideológico-culturais, em estabelecer 
socialmente esferas, sob o princípio da separação, embora vistas como iguais. Assim a divisão de propriedade, de recursos e trabalhos, segundo as diferenças cunhadas entre homens e mulheres, brancos e negros, proprietários e trabalhadores, colonizadores e colonizados, estruturarou o mundo administrado em visões hierárquicas, que deviam se justificar por si sós.

O romantismo europeu, por sua vez, reflete a ambiência então operante. O romantismo alemão, por exemplo - ainda que a princípio a Alemanha não estivesse unificada - , procura, nas raízes folclóricas, na tradição das narrativas orais, uma forma de sedimentar o seu cânone, com o culto ao Volksgeist, com forte valorização do dado local. Goethe então propõe o conceito de Literatura Universal (Weltliteratur), em atenção aos valores e crenças da modernidade europeia, sustentados na nação e em suas tradições, com a crença no progresso e na ciência.

A filosofia, então, reforçou o historicismo das metanarrativas. Hegel tem uma visão panteísta da História; para ele existe um espírito, uma intuição transcendental que constitui a origem criadora da realidade universal. A ideia evolui sob o signo da dialética do espírito. Sendo o real essencialmente o devir, este avança inexoravelmente rumo à marcha ternária da tese-antítese-síntese. A História, ao ser tomada como criação do espírito, não passa de uma manifestação exterior ao desenvolvimento da ideia; por isso, o curso da História segue uma linha evolutiva: os povos orientais (cultura místico-religiosa) representam a tese; a Antiguidade Clássica (cultura racional), a antítese; a Idade Moderna, a síntese.

Por outro lado, Augusto Comte, filósofo francês fundador da Sociologia, também bastante influenciado pelo racionalismo, via no progresso da Ciência a chave para a emancipação do gênero humano. Formaram-se assim, com o conhecimento religioso e a filosofia metafísica, explicações imaginárias presentes em setores da realidade social que ainda não haviam chegado ao conhecimento científico, completamente racional. Assim, a humanidade 
teria passado pelo estado religioso (politeísmo feiticista), metafísico (monoteísmo) até chegar ao estágio racional, preso à observação dos fatos (positivismo). Podemos notar que os três filósofos do século XIX, acima citados, têm uma visão presa ao continuísmo historicista e ao teleológico, com forte visão eurocêntrica, refletindo-se nas histórias da literatura daquele continente e daquelas advindas de sua colonização, como a história da literatura brasileira, por exemplo.

O Estruturalismo segue a tendência do cientificismo corrente, do final do século XIX e início do XX, quando reduz o texto literário a uma rede de significância e prioriza a langue, em sua abstração coletiva de uso, sob a justificativa de se debruçar sobre a estrutura do próprio signo para que fosse mais bem observado. Essa teoria padece do rigor racional, a que se impõe, tornando, muitas vezes, a análise do signo e da obra literária uma espécie de intervenção cirúrgica à procura de uma rede sistêmica de significância, encontrável no todo.

\section{O Estruturalismo no meio do caminho}

Ferdinand de Saussure, em Curso de linguística geral (1995), compilado por seu genro e discípulo Charles Bally, vai dizer que o código linguístico, dividido entre langue, sistema coletivo, e parole, de uso individual, constitui um sistema, uma estrutura, cujos elementos só significam na relação estabelecida com o todo; assim, para haver linguagem é necessário que o significante (cadeia fônica) e o significado (conteúdo) do signo estejam em relação de interdependência. Mas é com o Círculo Linguístico de Praga que o vocábulo "estrutura" ganha destaque com Mukarovsky, quando este fala em "estrutura melódica", "estrutura rítmica", "estrutura fônica", "estrutura sintática" e em "estrutura de conteúdo".

O Estruturalismo reforçou uma perspectiva, de certa sorte idealista, por enfatizar o significado, preso a uma essência de origem primeira, e não se ateve às condições enunciativas de sua realização; antes, a análise transitou dentro de um leque universal de estruturas. Por outro 
lado, expôs a literatura a uma espécie de previsibilidade e destituiu-a do inusitado, por ser elaborada a partir de algo anterior ao indivíduo.

Saussure, quando se refere ao sujeito falante, afirma que esse procede ao recorte da realidade, ao apresentar o signo linguístico como produto da união arbitrária entre o significante e o significado; mas, ao mesmo tempo, idealisticamente, incide sua análise na langue, isto é, na abstração do uso, e não na parole. Incorre, então, no equívoco de atribuir ao código linguístico, isto é, à soma de todos os signos desse código, o qualificativo natural, ao desconsiderar o contexto de uso. Com isso, submete o sujeito da enunciação à rede estrutural, que o cerceia.

Em Marxismo e filosofia da linguagem (2004), cuja primeira edição é de 1929, Bakhtin, partindo da díade língua e fala de Saussure, centra-se na fala. Saussure despreza-a, quando encerra seu foco de análise em um princípio estático, ao privilegiar um contrato coletivo, monológico, que transita pelo monismo do interdito, cuja potência do contínuo ocupa a virtualidade do desenvolvimento do discurso no intervalo entre $0-1$, do falso/verdadeiro, da denotação.

O revisionismo bakhtiniano, por outro lado, vê a linguagem, enquanto sistema de fala, que se sustenta em uma dinâmica combinatória, individual na troca dos signos, através do diálogo. Portanto, o dialogismo proposto refuta o monologismo e se sustenta na ambivalência, na negação como afirmação. E, ao transgredir o interdito 0-1 da lógica dominante, instaura o seu duplo: 0-2.

Ao opor o dialogismo ao monologismo, Bakhtin, em Problemas da poética de Dostoiévski (1981) e em $A$ cultura popular na Idade Média e no Renascimento(1987), reivindica para o texto literário a seara da ambivalência em que a palavra, isto é, o signo linguístico travejado pelo sujeito, destinatário e contexto, se expõe, através do conjunto de elementos sêmicos, em plenitude. Tal visada é capaz de carnavalizar o déjà $v u$, quando relativiza a noção de anterioridade, do erudito e do(a) autor(idade),em recalque do popular, da intertextualidade, da paródia. 
Há muito que o radicalismo do Estruturalismo vinha sofrendo fortes restrições. Barthes, em $S / Z$ (1970), ao analisar o conto Sarrasine, de Balzac, indaga-se sobre a possibilidade de o signo ser neutro, à luz da noção de Saussure, quando se refere ao código linguístico como algo capaz de fazer representar o chamado real, de forma autônoma, isenta de qualquer interesse, na medida em que, para haver linguagem, é preciso que significante e significado se remetam de forma arbitrária. E a crítica literária, até então, ao entender-se como metalinguagem, acabou por reduzir o texto a uma estrutura delimitada; entretanto, este deve ser tratado, enquanto escrita, em sua produtividade, enquanto o leitor, neste mesmo instante, é chamado a fazer parte dessa estruturação em aberto.

Barthes, assim, passa da obra ao texto e flagra a pretensão representativa da atitude natural da literatura chamada realista. Para ele, em vez de caracterizar o signo como natural, dever-se-ia vê-lo em sua intervenção sobre a realidade, pois, na literatura, não há originalidade, nem autor, e qualquer obra é produto da intertextualidade com outros escritos que a antecedem.

Tal pretensão, a de o signo ser visto como representação ou reflexo, em função simbólica, e neutro em sua nomeação, nega a sua própria condição de produtividade e, mais do que tudo, o fato de o mundo ser complexo e múltiplo.

O espaço bilateral da consciência simbólica, escreve Barthes, privilegia massivamente a semelhança, constrói uma relação analógica entre significante e significado que ignora a questão da forma e cria uma dimensão vertical do signo. Neste esquema, o significante é sempre pré-determinado pelo significado - aquele espaço conceitual ou real que é colocado anteriormente e de fora do ato da significação (BHABHA, 2003, p. 81-82).

É bom que se diga: o Pós-Estruturalismo já estava sendo gestado, de certa sorte, no Estruturalismo, quando 
este se voltou para a explicação do código linguístico, em seu funcionamento como linguagem. E a contestação do imaginário ocidental, com toda a sua entourage, amparado nas metanarrativas, bem como no beletrismo canônico, ganha dimensão nunca antes vista, em alguns momentos pontuais do século $\mathrm{XX}$, abalando a condição do próprio escritor. Entretanto, para Lyotard,

O artista ou o escritor pós-moderno está na posição de um filósofo. Em princípio, o texto que ele escreve, a obra que produz não são governados por regras preestabelecidas, e não podem ser julgados segundo um julgamento determinante, pela aplicação de categorias comuns ao texto ou à obra. São essas regras e categorias que a própria obra de arte está buscando (1989, p. 81).

OfimdaSegundaGuerra Mundial,aDescolonização de domínios europeus em outros continentes, a entrada dos filhos do operariado em Universidades Abertas, a ocupação da Tchecoslováquia, em 1968, por tropas soviéticas e, no mesmo ano, o movimento estudantil, em Paris, com o apoio das feministas, no famoso movimento de libertação das mulheres, constituem os principais acontecimentos desencadeadores do que veio depois no terreno da crítica.

A crítica, seja ao status quo, seja ao texto literário, requer, mais do que um empreendimento, antes um posicionamento político, de quem a faz, em forma de agência, em performance insidiosa. As teorias críticas então ganham uma dimensão muito mais ampla, na medida em que o teórico não pode mais se eximir do mundo. Nessa linha de ação, estão os Estudos Culturais, o Pós-Colonialismo e a Crítica Feminista.

No subitem seguinte, abordaremos melhor o pósestruturalismo, mais especificamente, na versão da teoria da desconstrução de Jacques Derrida e na crítica pósfeminista, quando explicitaremos seu tributo à teoria da desconstrução derridiana. 


\section{Em vias de revisão}

Ainda que não seja uma escola unificada de crítica à modernidade, o termo pós-estruturalismo começou a ser utilizado a partir de 1970, vinculado ao pós-modernismo, com Jean Baudrillard, Jean François Lyotard, Michel Foucault e Julie Deleuze e ao pós-criticismo, com Frederic Jameson, e à desconstrução, com Jacques Derrida.

Em Gramatologia (1973) e em L'écriture et la différence (1967), Derrida lança as bases da teoria da desconstrução, ao tentar desconstruir o pensamento logofonocêntrico, amparado em monismos, como o conceito de verdade $(\log o)$ e da palavra viva (fono), calcados na metafísica, quando vinculou a retórica à lógica e o estilo ao significado, como se a palavra oral estivesse imune aos efeitos da escrita. Com isso, multiplicidade, dissenso, conflito acabam reduzidos a "acidentes" (em oposição à substância), ou a mero artifício dialético provisório utilizado pela unidade subjacente do Espírito (PESSANHA, 1997, p. 80).

Para Derrida, a escrita — elemento de substituição - não deve ser vista como cópia servil à fala, pois toda linguagem é metafórica e tanto a filosofia, o direito, quanto a literatura são linguagens figuradas, que trabalham sempre para tornar a ambiguidade como injunção da verdade.

A metafísica ocidental, como limitação do sentido do ser no campo da presença, produz-se como a dominação de uma forma linguística. Interrogar a origem desta dominação não equivale a hipostasiar um significado transcendental, mas a questionar sobre o que constitui a nossa história e o que produziu a transcendentalidade mesma (DERRIDA, 1973, p. 28-29).

Derrida, então, ao questionar o princípio metafísico do significado transcendental (gramatologia), encontra, na conceituação saussuriana de signo, o mesmo princípio da significação fixa e estável. O signo, para justificar sua existência, precisa definir-se pelo que não é, pela sua ausência, ainda que simule a presença. $\mathrm{Na}$ concepção 
estruturalista, o signo só se torna linguagem quando há a relação de significância estabelecida, a chamada dupla articulação, entre significante (cadeia fônica), composto por seus fonemas, e significado (evocação mental de um ser ou de algo).

Portanto, o significante só existe porque se opõe, se diferencia de outro significante, que remete a outro significado, que não o primeiro, sempre em um processo de adiamento da perfeita articulação entre significante e significado. O significadoé, pois, o resultado de uma cadeia de significantes sem referentes ou significados estáveis. $\mathrm{O}$ que se toma como significado é, de fato, um significante, do qual se interrompeu o jogo de disseminação.

Resta aí sempre um componente de significado que, na pauta da metafísica ocidental, não foi incluído e ao qual Derrida chama de suplemento. Tal excesso, em outras palavras, não se encontra representado no código linguístico nem, consequentemente, em todo o sistema de atribuição de sentido. A différance - vocábulo oriundo de dois verbos da língua francesa, différer (adiar, diferir) e diférer (citar, deferir) - encerra a noção de que o signo diferencia, cita e, ao mesmo tempo, adia a significação completa de algo (COSTA LIMA, 1988).

Descamps, em Asideias filosóficas contemporâneas na França (1991), elucida-nos como ocorre essa condição do signo, de certa sorte, precária:

Os mecanismos de autoafetação, de "diferança", destroem a linha régia da presença em si. Deslocar as figuras da identidade, da origem, é desconstruir as oposições seculares entre natureza/cultura, presença/ausência, sujeito/objeto, inteligível/ sensível. A tarefa é imensa já que esses rochedos não param de frequentar os grandes textos (DESCAMPS, 1991, p. 111).

Logo, a desconstrução centra sua crítica aos monismos, que se opõem ao dialogismo, ao pluralismo, à diferença, quando incide suas análises em textos que, com o objetivo de evidenciar a vulnerabilidade de 
significação, balizaram todos os centros excludentes dos pares dicotômicos ocidentais: centro/periferia, branco/ negro, homem/mulher etc.

\section{Pós-feminismo e desconstrução}

Ao feminismo costuma-se atribuir ondas: o "universalismo", de que existe "um sexo", das primeiras feministas; o "diferencialismo", que resiste ao "uno", "Esse sexo que não é sexo" (IRIGATAY, 1985); e a ginocrítica, com as teóricas da escrita (CIXOUS, 1995; KRISTEVA, 1980). Essas duas ondas são tachadas de sexistas e binaristas, por se manter no racionalismo cartesiano da identidade de gênero essencialista, isto é, como algo fechado e identificável, sustentado na díade da exclusão: ou, ou. Dessa sorte, ainda acreditavam nas promessas emancipatórias das metanarrativas da modernidade não postas em prática até então. Entretanto, impõe-se um aparato revisionista da lógica da tradição ocidental, com a noção de que o "sexo não é um, nem dois" (BUTLER, 1999), em nome da inclusão "e, e"; que leva à teoria "queer", em sua subversão das identidades sexuais, uma vez que tanto o sexo, como o gênero são construções discursivas de poder. Na mesma linha de raciocínio, Foucault, em Microfísica do poder (2008), afirma:

O que faz com que o poder se mantenha é simplesmente que ele não pesa só como uma força que diz não, mas que de fato ele permeia, produz coisas, induz ao prazer, forma prazer, produz discurso. Deve-se considerá-lo como uma rede produtiva que atravessa todo o corpo social muito mais do que uma instância negativa que tem por função reprimir [...]. A verdade é deste mundo; ela é produzida nele graças às múltiplas coerções e nele produz efeitos regulamentados de poder. Cada sociedade tem seu regime de verdade, sua "política geral" de verdade: isto é, os tipos de discurso que ela acolhe e faz funcionar como verdadeiros (FOUCAULT, 2008, p. 8-12). 
A crítica pós-feminista, assim, relaciona sinais de exaustão a uma série de discursos redutores que embasaram a instituição da diferença reificada, que organiza a diferença na desigualdade (RICHARD, 2002, p. 161), uma vez que mantêm as categorias de sujeito e varão, como parâmetro de legitimação dos discursos. Tal equívoco foi cometido mesmo por feministas, como Simone de Beauvoir de O segundo sexo (1980), texto publicado em 1949, quando se manteve ainda no mesmo para tratar da diferença, em uma posição binária e vicária da mulher, centrada em um outro, que lhe dava sentido. Nas palavras ainda de Nelly Richard, em Intervençôes críticas: arte, cultura, gênero e política (2002):

A nova crítica feminista compartilha o argumento pós-metafísico de que as mulheres já não podem descansar na substancialização de um "nós", reunificador do heterogêneo e do descontínuo de suas múltiplas e contraditórias articulações de identidade. Ao mesmo tempo, o feminismo não pode renunciar completamente à ideia de que um traço de união reagrupe "as mulheres", sob a referência coletiva de um "nós", uma vez que sem a base operacional desse "nós" não existe luta política (RICHARD, 2002, p. 163).

O que ela defende é que, para a efetiva emancipação da mulher, esta deve se colocar nas referências e representações que sempre a identificaram; mas, ao mesmo tempo, de modo atento e vigilante, transpor o pré-dado, em um processo de resistência/negociação, para, de fato, avançar em seu empoderamento, enquanto ser dotado de razão e de querer. Desta sorte, é salvado o melhor da dialética, porque entendemos que a síntese do pensamento dialético é, para a efetiva mudança, somente um por enquanto, do nada definitivo das identidades, em articulações contingentes do "eu" com o "nós".

Os estudos de Derrida já citados aqui, ao se contrapor às oposições binárias, colocam o significado do sujeito em deslizamento e constituem, por isso, uma 
ferramenta importante para o entendimento de que toda exclusão se radica em uma construção discursiva e não em algo pré-dado e insubstituível, de modo ontológico; e amplia a questão do sentido para qualquer tipo de violência capaz de silenciar. Já Butler (1999) justifica o processo classificatório de toda identidade, ao afirmar que são construções discursivas elaboradas e colocadas sobre a mulher, racializando e etnicizando seu corpo de um exterior, de um domínio de efeitos inteligíveis (1999, p. 22).

Assim, ao refutar os essencialismos, Butler defende a questão da performatividade, enquanto produção de identidade, porque "descola" o fenômeno da produção discursiva do mesmo. A partir desta, é possível perceber que os sistemas de representação estão inegavelmente ligados ao poder; e, ao resgatarem a materialidade do significante, evidenciam a pretensão clássica de priorizar o significado. Nesse momento, a diferença surge, em contrapartida, ao mesmo, representado pelo etnocentrismo ou pelo gênero.

Logo, a mulher deve ser evidenciada em sua dinâmica existencial que dê conta do seu gênero, de sua classe e de sua etnia, em seu relacionamento diuturno contextualizado.

A discussão acerca das relações de gênero, sem uma perspectiva da etnia e da classe social a que pertence a mulher, coloca o debate em descompasso com os acontecimentos. Se falarmos, em termos de discursos emancipatórios, ainda no século XVIII, os homens foram chamados a responder ao patriarcalismo, esteado no branco europeu. Enquanto as mulheres brancas foram privadas da noção de igualdade e liberdade, ação contrária, portanto, ao princípio da universalização da igualdade e da unidade do gênero humano. Somado a isso, o discurso da ciência se encarregou de plasmar uma série de pré-conceitos misóginos, contrários à mulher 
e também aos representantes de outras etnias que não a branca. (SACRAMENTO, 2009, p. 217-218).

Para Butler, há, na concepção de sujeito visto pelas feministas anteriores um essencialismo particular condicionado à transcendência. Propõe então uma genealogia crítica do gênero complementada por uma

Política de atos performativos de gênero, que reescreva as identidades de gênero existentes e, ao mesmo tempo que ofereça um enfoque prescritivo sobre o tipo de realidade de gênero que deveria existir. (BUTLER, 1998, p. 313; tradução minha do espanhol)

Os atos performativos então têm a função de desarticular os termos da dialética um/outro e subverter a normalidade organizada sobre bases binárias. Butler, ao propor a "quebra" da díade sexo-gênero - sendo o primeiro já uma construção cultural-discursiva, tal como foi visto por Freud ("a anatomia da mulher é destino") - pode colocar a mulher, desse modo, disponível ao desejo, porque se utiliza da agência, em pontos de fuga (BUTLER, 2003).

Com a expansão do feminismo negro, feminismo lésbico, feminismo popular, ecofeminismo, feminismo cristão, e assim por diante, a segunda metade dos anos 80 e os anos 90 [com o Queer Studies] viram a proliferação de novas protagonistas cujas trajetórias político-pessoais diferiam de modo significativo daquelas das primeiras feministas (referidas agora como "históricas") [...]. (ALVAREZ, 2000, p. 393).

Os discursos das chamadas "feministas históricas" incidiam basicamente sobre reivindicações, sobre a crítica da mulher branca e de classe média ao patriarcalismo ocidental, porque ainda trabalhavam em bases dicotômicas, ancoradas no edifício filosófico de 
racionalidade ocidental, essas, em si mesmas, excludentes, do alto/baixo, claro/escuro, natureza/cultura, homem/ mulher, centro/periferia.

O pós-feminismo, hoje, ainda que multifacetado, como se constata na citação de Alvarez (2000), defende, em sua plataforma, a ideia de que a igualdade de gênero não pode ser vista sem uma contextualização, em uma perspectiva culturalista, em que categorias como gênero, classe e etnia, que serviram, no passado, para marcar a diferença, hoje devem ser utilizadas em realocações desdobráveis, como marca disjuntiva da presença, contrárias às metanarrativas, quando se colocavam de modo totalizador.

\section{Considerações finais}

As metanarrativas da tradição ocidental, vindas desde a Grécia da Antiguidade Clássica, com atualizações durante a modernidade, ainda que se dissessem respaldadas em princípios racionais e universais, não conseguiram incluir em seus relatos toda a gama de complexidade do gênero humano. E trabalharam com pares dicotômicos, como forma de organizar os fenômenos, que balizaram juízos de valor, cujo segundo elemento encerrava o outro, o excluído, sempre a partir do primeiro, do mesmo.

Vários movimentos, durante o século $\mathrm{XX}$, impuseram-se, em oposição, ao logos ortodoxo da tradição ocidental e criticaram sobremodo o seu modelo, ainda que o foco principal tenha se centrado sobre a modernidade. Entre essas correntes, encontram-se o pós-estruturalismo, a teoria da desconstrução e, muito tributário à última, o pós-feminismo.

O pós-estruturalismo e a desconstrução estiveram atentos ao paradigma arrogante da modernidade, sustentado, segundo Derrida (1973), no logofonocêntrico, isto é, no princípio da monologia, que se opõe ao pluralismo. Tal princípio assenta-se no conceito de verdade excludente $(\log o)$ e supõe que a representação é a palavra viva (fono). 
O pós-feminismo, amparado na teoria da desconstrução derridiana, contesta as duas primeiras ondas do feminismo, porque, em suas reivindicações, ainda trabalharam em favor do logos da modernidade, amparado no ou, ou; portanto, ainda, em pares hierárquicos, ao acreditar nas promessas das metanarrativas emancipatórias do racionalismo cartesiano. A pós-feminista Butler (1999), ao rever a lógica da tradição ocidental, defende que o sexo não é um, nem dois e que tanto o gênero quanto o sexo são construções discursivas, formatadas para o desejo da heterossexualidade. Dessa sorte, acena com a inclusão $e$, $e$ e a posterior teoria queer, que subverte as identidades sexuais atreladas ao sexo-gênero-desejo. 


\section{Referências}

ALVAREZ, S. E. A. A "globalização" dos feminismos latinoamericanos: tendências dos anos 90 e desafios para o novo milênio. In: ALVAREZ, S.; DAGNINO, Evelina; ESCOBAR, Arturo (Orgs.). Cultura e política nos movimentos sociais latino-americanos: novas leituras. Belo Horizonte: UFMG, 2000. p. 383-426.

BAKHTIN, M. A cultura popular na Idade Média e no Renascimento: o contexto de François Rabelais. Trad. Yara Frateschi Vieira. São Paulo: Hucitec; Ed. UnB, 1987.

BAKHTIN, M. Marxismo e filosofia da linguagem. Trad. Michel Lahud e Yara Frateschi Vieira. São Paulo: Hucitec, 2004.

BAKHTIN, M. Problemas da poética de Dostoiévski. Trad. Paulo Bezerra. Rio de Janeiro: Forense Universitária, 1981.

BARTHES, R. S/Z. Paris: Seuil, 1970.

BEAUVOIR, S. O segundo sexo. Trad. Sergio Milliet. Rio de Janeiro: Nova Fronteira, 1980.

BHABHA, H. O local da cultura. Trad. Myria Ávila, Eliana Lourenço de Lima Reis e Gláucia Renate Gonçalves. Belo Horizonte: UFMG, 2003.

BUTLER, J. Corpos que pesam: sobre os limites discursivos do "sexo". In: BUTLER, J.; LOPES LOURO, G. (Orgs.). $O$ corpo educado: pedagogias da sexualidade. Belo Horizonte: Autêntica, 1999.

BUTLER, J. Problemas de gênero: feminismo e subversão da identidade. Trad. Renato Aguiar. Rio de Janeiro: Civilização Brasileira, 2003.

BUTLER, J. Actos performativos y construción del gênero: um ensayo sobre fenomenoloía y teoria feminista. In: BUTLER, J. Debate feminista. vol. 18, 1998, p. 113. 
CIXOUS, H. La risa de la medusa. Trad. revisada por Myriam Díaz-Diocaretz. Barcelona: Anthropos, 1995.

COSTA LIMA, L. O fingidor e o censor. Rio de Janeiro: Forense Universitária, 1988.

DERRIDA. J. Gramatologia. São Paulo: Perspectiva, 1973.

DERRIDA. J. L'écriture et la diffèrence. Paris: Seuil, 1967.

DESCAMPS, C. As ideias filosóficas contemporâneas na França. Trad. de Arnaldo Marques. Rio de Janeiro: Jorge Zahar Editor, 1991.

FOUCAULT, M. Microfísica do poder. Trad. de Roberto Machado. Rio de Janeiro: Graal, 2008.

HEGEL, F. Fenomenologia do espírito. Trad. Paulo Meneses. Petrópolis: Vozes, 2003.

KRISTEVA, J. Pouvoirs de l'horreur: essai sur l'abjection. Paris: Seuil,1980.

LYOTARD, Jean-F. A condição pós-moderna. Trad. José Bragança de Miranda. Lisboa: Gradiva, 1989.

PESSANHA, J. A. M. Cultura como ruptura. In: BORNHEIM, G. et al. Tradição/ Contradição. Rio de Janeiro, Jorge Zahar Editor/Funarte, 1997.

RICHARD, N. Intervenções críticas: arte, cultura, gênero e política. Trad. Rômulo Monte Alto. Belo Horizonte: UFMG, 2002.

SACRAMENTO, S. A mulher negra e a cidadania negada em Jubiabá de Jorge Amado. Revista Terceira Margem (UFRJ), Rio de Janeiro, n. 20, p. 215-229, janeiro-julho 2009.

SAUSSURE, F. Curso de linguística geral. Trad. Antônio Chelini et al. São Paulo: Cultrix, 1995. 